\title{
Analysis of 50-, 100-, and 200-m Freestyle Swimmers at the 1992 Olympic Games
}

\author{
Raul Arellano, Peter Brown, \\ Jane Cappaert, and Richard C. Nelson
}

The performances of 335 male and female swimmers competing in 50-, 100-, and 200-m freestyle events at the 1992 Barcelona Olympic Games were videotaped and analyzed to determine stroke length (SL), stroke rate (SR), starting time (ST), turning times ( $\mathrm{TI}=$ turn in, TO = turn out), finishing (end) time (ET), and average velocity (AV); relationships were then determined among these variables in addition to height, weight, age, and final time (FT). Differences were subsequently assessed within and among the events, and comparisons were made between male and female performances. ST, TI, TO, ET, and SL were identified as principal components of successful swimming performance at each distance. Results revealed statistically significant correlations between factors for all events. The men were older and taller; possessed longer stroke lengths; and started, turned, and swam faster than the women. As the race distance increased from 50 to $200 \mathrm{~m}, \mathrm{ST}$, TI, TO, SL, and ET increased for both men and women, while age, SR, and AV decreased.

Competitive swimming performances have demonstrated consistent and significant improvement over the past 3 decades. The reasons for such improvement are many but are due in part to advanced training procedures, sophisticated selection methods, and superior stroke mechanics. While the international racing field as a whole continues to perform faster times (i.e., from one Olympiad to the next), rates of improvement and actual race velocities vary among events and race distances as well as between male and female competitors. Consequently, .numerous questions arise as to how and why these differences occur.

Several investigators (e.g., Craig \& Pendergast, 1979; DeGaray, Levine, \&

R. Arellano is with the Facultad de las Ciencias de la Educacion Fisica Y el Deporte, Universidad de Granada, Carretera de Alfacar, 48, 18011 Granada, Spain. P. Brown and R.C. Nelson are with the Biomechanics Laboratory, Pennsylvania State University, University Park, PA 16802. J. Cappaert is with the International Center for Aquatic Research, USOC, 1750 E. Boulder St., Colorado Springs, CO 80909-5760. Request reprints from R.C. Nelson. 
Carter, 1974; Grimston \& Hay, 1986) have examined the factors influencing elite swimming performance. A primary focus of these studies has been the race velocity components, stroke rate $(\mathrm{SR})$ and stroke length $(\mathrm{SL})(\mathrm{V}=\mathrm{SR} \times \mathrm{SL})$. In many cases, similar swimming performances have demonstrated greater variability in SL than in SR (Craig \& Pendergast, 1979; Craig, Skehan, Pawelczyk, \& Boomer, 1985; East, 1970; Hay \& Guimares, 1983). Several factors may influence the SR-SL relationship and thus affect swimming velocity. Some of the parameters examined include body height, arm and leg length, and hand size (Clarys, Jiskoot, Rijken, \& Brouwer, 1974; DeGaray et al., 1974; Grimston \& Hay, 1986). Grimston and Hay (1986) suggested that swimming velocity is affected very little by the swimmer's physique, but the combination of SR and SL used to attain a given swimming velocity is very much a function of body size. However, previous investigators (Poe, 1969; Shotwell, 1972; Smith, 1959, 1978; Stroup, 1964) have reported low correlations between height and final time (FT) for both males and females.

Two additional aspects of swimming performances at the world-class level deserve further investigation. First, elite male swimmers typically swim faster ( $10 \%$ on average) than their female counterparts. It would appear, then, that the evaluation of differences in age, height, and swimming parameters between Olympic-level male and female competitors is worthwhile. East (1970), in his comparison of males and females in the same swimming events, found that males had longer stroke lengths but that stroke rates were similar. He concluded that the longer stroke length produced by men was most likely the result of greater propulsive force. A number of investigators have indicated that greater swimming speeds attained by males are due to greater stroke lengths. Typically, females and males have similar stroke frequencies (Craig et al., 1985 [excluding freestyle]; East, 1970). Second, it is also evident that the various race components (i.e., starting time, turning time, finishing time) have a direct bearing on the outcome of any race. It stands to reason, then, that a comparison of the relative importance of these components at different race distances would be of merit.

The previously reported research investigations concerning various aspects of swimming performance have often been somewhat narrow in scope. Specifically, the studies usually consisted of relatively small sample sizes or lacked the presence of elite swimmers (i.e., Olympic-level swimmers) or were conducted under training or experimental conditions. Many studies were restricted to one gender, to only one or two swimming events, or to only three or four experimental variables. A project that overcame many of these limitations was conducted at the 1988 Seoul Olympic Games (Chengalur \& Brown, 1992; Kennedy, Brown, Chengalur, \& Nelson, 1990). Specifically, the Seoul studies examined elite male and female swimmers competing in all four swimming strokes. The availability of modern video recording and computer analysis techniques made it possible to efficiently and accurately study nearly 400 competitors. The basic data for the analytical part of the study consisted of age, height, stroke rate, stroke length, and final time for male and female competitors in all 100- and 200-m singlestroke events. Stroke length was identified as the single most important factor affecting the final time achieved in the 100 - and $200-\mathrm{m}$ events, while a strong relationship was shown between height and final time.

The present investigation replicated and expanded upon the Seoul Olympic Games studies. The basic data for the analytical part of the investigation consisted 
of the age, height, weight, stroke rate (SR), stroke length (SL), starting time (ST), turning times (turn in, TI; turn out, TO), finishing time (ET), average velocity (AV), and final time (FT) for the male and female competitors in the 50-, 100-, and 200-m preliminary and final freestyle events at the 1992 Barcelona Olympic Games. Because of the strong relationship between height and body weight $(r=.79-.85)$, the results for weight are not included here. Furthermore, from a practical standpoint, height is more closely associated with technique and performance than is body weight. The purposes of the study were as follows: (a) to evaluate the intercorrelations among nine experimental variables for men and women, (b) to compare and contrast the male and female swimmers, and (c) to examine the differences across the three race distances. The subjects included 335 Olympic swimmers, 200 men and 135 women.

\section{Methods}

The swimming events at the Barcelona Olympic Games, July 26-31, 1992, were videotaped by a four-person crew using Panasonic AG-450 S-VHS cameras at $60 \mathrm{~Hz}$ sampling rate. All preliminary and final heats were recorded for both men and women. The events analyzed in this study were the men's and women's 50-, $100-$, and $200-\mathrm{m}$ preliminary and final freestyle heats.

The video cameras were located above the top row of permanent spectator seats, $10 \mathrm{~m}$ above and $25 \mathrm{~m}$ from the near side of the pool. The first camera was positioned to cover the start and the first $10 \mathrm{~m}$, the second videotaped the middle $30 \mathrm{~m}$ of the racecourse, while the third recorded the final $7.5 \mathrm{~m}$ at the turning end. From its fixed position, each camera was able to capture its respective portion of the race for all competitors. This study utilized recordings from all three cameras. The pool was divided into 10 lanes by floating buoys that alternated in color every $5 \mathrm{~m}$ and served as calibration markers for distance measurements. The two outside lanes were not used for competition, thus limiting the maximum number of swimmers per race to eight.

VHS copies of the S-VHS originals were used in the analysis of the swimming events. The recording rate of the AG-450 is 60 fields/s. The video playback system (Panasonic AG-6300) interlaced two consecutive fields to create a video frame, thereby producing 30 frames/s. This frame rate was considered adequate for this investigation, since the motion of the swimmers is relatively slow, and only above-water performance was recorded. An AST premium 286 computer, with BCD Associates video controller circuit board, was interfaced to the video playback system. A program designed by Peak Performance Technologies, Inc., was used to sequentially encode every frame of the tape with a number on Audio Track 2. When a frame was played back on the AG-6300, the computer was able to detect which frame number was currently being played; thus the time between any two given frames was determined with an accuracy of $1 / 30 \mathrm{~s}$. This method was deemed sufficiently accurate for the data being generated.

The self-reported age and height of each swimmer were taken from a master computerized list obtained at the Olympics swimming venue in Barcelona (courtesy of Rafael Escalas). Final times were obtained from the Official Swimming Results of the XXV Olympiad at Barcelona (1992). These values, together with temporal data obtained from the tapes, were used to determine stroke rate and stroke length for each competitor in each race. 


\section{Data Calculations}

The four-cycle method for estimating stroke rate, utilized by Kennedy et al. (1990), was the basis for the five-cycle method used in this study. Specifically, the time required to perform five complete stroke cycles (5ST) was measured and then used to calculate the stroke rate: $\mathrm{SR}=5 / 5 \mathrm{ST}$ strokes/s. The average swimming velocity (AV), which was determined for the midsection of the pool, was used in conjunction with the stroke rate data to determine the stroke length as follows:

$$
\begin{aligned}
\mathrm{V} & =\mathrm{Li} / \mathrm{Ti}(\mathrm{m} / \mathrm{s}) \\
\mathrm{SL} & =\mathrm{SR} / \mathrm{V}(\mathrm{m} / \text { cycle })
\end{aligned}
$$

where $\mathrm{Li}=$ length in meters of midsection of $\mathrm{Lap} \mathrm{i}$, and $\mathrm{Ti}=$ time in seconds to cover the midsection of Lap $i$. The lane buoys in the pool were used as distance markers. The midsection length for the laps was $30 \mathrm{~m}, 32.5 \mathrm{~m}$, or $35 \mathrm{~m}$. The distance varied depending on race distance and the race lap analyzed: $\mathrm{Li}=32.5$ for the starting lap in 100 - and $200-\mathrm{m}$ events $(\mathrm{ST}+\mathrm{Li}+\mathrm{TI}), \mathrm{Li}=32.5 \mathrm{~m}$ for the final lap in 100- and $200-\mathrm{m}$ events ( $\mathrm{TO}+\mathrm{Li}+\mathrm{ET}$ ), $\mathrm{Li}=35 \mathrm{~m}$ for the middle laps in $200-\mathrm{m}$ events $(\mathrm{TO}+\mathrm{Li}+\mathrm{TI})$, and $\mathrm{Li}=30 \mathrm{~m}$ for the single lap of the 50-m events $(\mathrm{ST}+\mathrm{Li}+\mathrm{ET})$. For each lap an imaginary line was interpolated between the distance markers of each lane, and the time required to swim this distance (Ti) was calculated with the previously described software from Peak Performance Technologies. All results were calculated with a database program developed by the research group.

Similar procedures were followed when we assessed the starting time (first $10 \mathrm{~m}$ ), turning time $(7.5 \mathrm{~m}$ in and $7.5 \mathrm{~m}$ out) and finishing time (final $10 \mathrm{~m}$ ). An electronic flash, activated at the same instant that the starter's pistol was fired, made it possible to detect the precise instant at which each swimming race began. Thus, starting times were determined by detecting the starting flash on the video screen (and resultant frame number) and then forwarding the race to the frame when each competitor crossed the interpolated $10-\mathrm{m}$ line of the race. We calculated turning-in time by first marking on the video screen an appropriate line, $7.5 \mathrm{~m}$ from the end of the pool, and then capturing the frame when a competitor's head intersected that line and the subsequent frame when that swimmer made initial contact with the turning wall. The method for determining turning-out time was simply a reversal of the turning-in process. Finishing time was calculated in a manner identical to turning-in time, beginning at a $10-\mathrm{m}$ distance from the end of the pool.

\section{Statistical Analyses}

Data from both preliminary and final heats were used in the analysis. For a swimmer who competed in both heats, the time for the best performance was utilized. The data from each heat in the men's $50-\mathrm{m}$ freestyle were combined to form one master database on which the statistical analyses were performed. The same procedure was followed for the women's $50-\mathrm{m}$ freestyle, as well as the men's and women's 100 - and $200-\mathrm{m}$ freestyle events. All calculations were performed on a Macintosh computer with StatView 512+ software (Abacus Concepts, Inc.). 


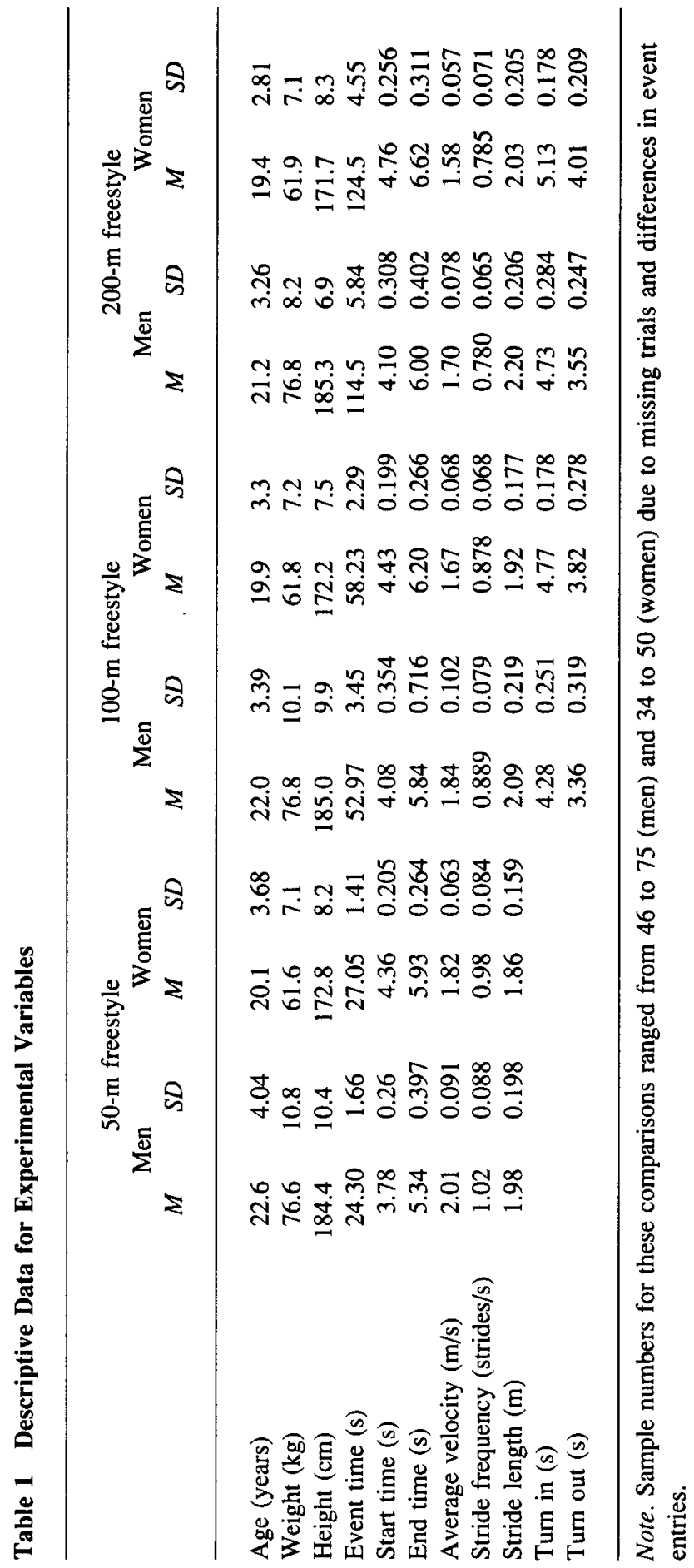


Mean and standard deviation values were then determined for all variables as presented in Table 1. Correlation coefficients were determined among the experimental variables, with the significance level set at .05. For each dependent variable, differences in values obtained between males and females and across events were evaluated with one-factor ANOVAs.

\section{Results}

\section{Variable Interrelationships}

The correlation coefficients determined among the nine experimental parameters are shown in Tables 2 through 7 for both males and females. The correlations between SL and SR for both men and women were high, with $r$ values ranging from -.83 to -.94 . This finding is consistent with previous investigations and further signifies the interdependence of these two variables (Kennedy et al., 1990).

Table 2 Correlation Coefficients: Men's 50-m Freestyle (Ns, 59-71)

\begin{tabular}{lcccccc}
\hline & Height & $\begin{array}{c}\text { Event } \\
\text { time }\end{array}$ & $\begin{array}{c}\text { Start } \\
\text { time }\end{array}$ & $\begin{array}{c}\text { End } \\
\text { time }\end{array}$ & $\begin{array}{c}\text { Average } \\
\text { velocity }\end{array}$ & $\begin{array}{c}\text { Stride } \\
\text { frequency }\end{array}$ \\
\hline Event time & $-.69^{*}$ & & & & & \\
Start time & $-.60^{*}$ & $.89^{*}$ & & & & \\
End time & $-.64^{*}$ & $.97^{*}$ & $.76^{*}$ & & & \\
Average velocity & $.63^{*}$ & $-.98^{*}$ & $-.83^{*}$ & $-.90^{*}$ & & .00 \\
Stride frequency & -.20 & -.01 & .13 & -.22 & $-.89^{*}$ \\
Stride length & $.56^{*}$ & $-.62^{*}$ & $-.50^{*}$ & $-.59^{*}$ & $.63^{*}$ & -.82 \\
\hline
\end{tabular}

*Significant $(p<.05)$.

Table 3 Correlation Coefficients: Women's 50-m Freestyle (Ns, 42-50)

$\begin{array}{cccccc}\text { Height } & \begin{array}{c}\text { Event } \\ \text { time }\end{array} & \begin{array}{c}\text { Start } \\ \text { time }\end{array} & \begin{array}{c}\text { End } \\ \text { time }\end{array} & \begin{array}{l}\text { Average } \\ \text { velocity }\end{array} & \begin{array}{c}\text { Stride } \\ \text { frequency }\end{array}\end{array}$

\begin{tabular}{lcccccc} 
Event time & $-.55^{*}$ & & & & & \\
Start time & $-.43^{*}$ & $.90^{*}$ & & & \\
End time & $-.56^{*}$ & $.88^{*}$ & $.69^{*}$ & & & \\
Average velocity & .23 & $-.97^{*}$ & $-.82^{*}$ & $-.69^{*}$ & & \\
Stride frequency & $-.35^{*}$ & -.05 & .15 & .06 & -.04 & \\
Stride length & $.46^{*}$ & $-.49^{*}$ & $-.46^{*}$ & $-.52^{*}$ & $.42^{*}$ & $-.92^{*}$ \\
\hline
\end{tabular}

*Significant $(p<.05)$. 
Table 4 Correlation Coefficients: Men's 100-m Freestyle ( $\mathrm{Ns}, 66-75)$

\begin{tabular}{lcccccccc}
\hline & \multicolumn{1}{c}{ Event } & $\begin{array}{c}\text { Start } \\
\text { time }\end{array}$ & $\begin{array}{c}\text { End } \\
\text { time }\end{array}$ & $\begin{array}{c}\text { Average } \\
\text { velocity }\end{array}$ & $\begin{array}{c}\text { Stride } \\
\text { frequency }\end{array}$ & $\begin{array}{c}\text { Stride } \\
\text { length }\end{array}$ & $\begin{array}{c}\text { Turn } \\
\text { in }\end{array}$ \\
& Height & & & & & & & \\
Event time & $-.75^{*}$ & & & & & & & \\
Start time & $-.77^{*}$ & $.91^{*}$ & & & & & & \\
End time & $-.54^{*}$ & $.70^{*}$ & $.66^{*}$ & & & & & \\
Average velocity & $.72^{*}$ & $-.96^{*}$ & $-.84^{*}$ & $-.49^{*}$ & & & & \\
Stride frequency & -.22 & .05 & .09 & .08 & -.06 & & & \\
Stride length & $.58^{*}$ & $-.57^{*}$ & $-.54^{*}$ & $-.33^{*}$ & $.59^{*}$ & $-.83^{*}$ & & \\
Turn in & $-.65^{*}$ & $.93^{*}$ & $.82^{*}$ & $.63^{*}$ & $-.90^{*}$ & .08 & $-.54^{*}$ & \\
Turn out & $-.77^{*}$ & $.91^{*}$ & $.86^{*}$ & $.66^{*}$ & $-.84^{*}$ & -.00 & $-.47^{*}$ & $.82^{*}$ \\
& & & & & & & & \\
\hline
\end{tabular}

*Significant $(p<.05)$.

Table 5 Correlation Coefficients: Women's 100-m Freestyle ( $\mathrm{Ns}, 45-48)$

$\begin{array}{cccccccc}\text { Event } & \text { Start } & \text { End } & \text { Average } & \text { Stride } & \text { Stride } & \text { Turn } \\ \text { Height } & \text { time } & \text { time } & \text { time } & \text { velocity } & \text { frequency } & \text { length } & \text { in }\end{array}$

\begin{tabular}{lccccccccc} 
Event time & $-.52^{*}$ & & & & & & & \\
Start time & $-.47^{*}$ & $.62^{*}$ & & & & & & \\
End time & $-.31^{*}$ & $.77^{*}$ & $.58^{*}$ & & & & & \\
Average velocity & $.47^{*}$ & $-.98^{*}$ & $-.51^{*}$ & $-.68^{*}$ & & & & \\
Stride frequency & -.25 & .27 & .22 & .15 & -.22 & & & \\
Stride length & $.41^{*}$ & $-.64^{*}$ & $-.37^{*}$ & $-.42^{*}$ & $.61^{*}$ & $-.90^{*}$ & & \\
Turn in & $-.36^{*}$ & $.90^{*}$ & $.49^{*}$ & $.61^{*}$ & $-.90^{*}$ & .16 & $-.52^{*}$ & \\
Turn out & $-.52^{*}$ & $.71^{*}$ & $.47^{*}$ & $.47^{*}$ & $-.64^{*}$ & $.51^{*}$ & $-.67^{*}$ & $.52^{*}$ \\
& & & & & & & & \\
\hline
\end{tabular}

*Significant $(p<.05)$.

The most prominent and meaningful $r$ values obtained at each race distance for both men and women were those for AV and FT (-.96 to -.99), SL and FT $(-.49$ to -.62$)$, ST and FT (.62 to .91), and ET and FT (.70 to .97). In addition, for races involving one or more turns, the correlations between TI and FT (.88 to .93) and TO and FT (.71 to .91) proved striking as well. In essence, then, the better swimmers started, turned, and finished faster while performing with longer stroke lengths. Previous studies have revealed the importance of stroke length as a determinant of fast swimming; however, few have identified the relative significance of ST, ET, FT, TI, and TO. It is readily apparent from this investigation that these factors play an important role in 50-, 100-, and 200-m freestyle race performance.

Relationships between height and FT (-.50 to -.75) were also high, indicat- 
Table 6 Correlation Coefficients: Men's 200-m Freestyle ( $\mathrm{Ns}, 46-54)$

\begin{tabular}{lcccccccc}
\hline & \multicolumn{1}{c}{$\begin{array}{c}\text { Event } \\
\text { time }\end{array}$} & $\begin{array}{c}\text { Start } \\
\text { time }\end{array}$ & $\begin{array}{c}\text { End } \\
\text { time }\end{array}$ & $\begin{array}{c}\text { Average } \\
\text { velocity }\end{array}$ & $\begin{array}{c}\text { Stride } \\
\text { frequency }\end{array}$ & $\begin{array}{c}\text { Stride } \\
\text { length }\end{array}$ & $\begin{array}{c}\text { Tum } \\
\text { in }\end{array}$ \\
\hline Event time & $-.71^{*}$ & & & & & & & \\
Start time & $-.66^{*}$ & $.80^{*}$ & & & & & & \\
End time & $-.62^{*}$ & $.84^{*}$ & $.57^{*}$ & & & & & \\
Average velocity & $.67^{*}$ & $-.99^{*}$ & $-.76^{*}$ & $-.82^{*}$ & & & & \\
Stride frequency & -.19 & .05 & .19 & .00 & -.03 & & & \\
Stride length & $.52^{*}$ & $-.55^{*}$ & $-.56^{*}$ & $-.42^{*}$ & $.53^{*}$ & $-.86^{*}$ & & \\
Turn in & $-.73^{*}$ & $.93^{*}$ & $.76^{*}$ & $.78^{*}$ & $-.89^{*}$ & .12 & $-.56^{*}$ & \\
Tum out & $-.63^{*}$ & $.91^{*}$ & $.80^{*}$ & $.68^{*}$ & $-.86^{*}$ & .06 & $-.50^{*}$ & $.88^{*}$ \\
\hline
\end{tabular}

*Significant $(p<.05)$.

Table 7 Correlation Coefficients: Women's 200-m Freestyle $(\mathrm{Ns}, 34-37)$

\begin{tabular}{lcccccccc}
\hline & \multicolumn{1}{c}{$\begin{array}{c}\text { Event } \\
\text { time }\end{array}$} & $\begin{array}{c}\text { Start } \\
\text { time }\end{array}$ & $\begin{array}{c}\text { End } \\
\text { time }\end{array}$ & $\begin{array}{c}\text { Average } \\
\text { velocity }\end{array}$ & $\begin{array}{c}\text { Stride } \\
\text { frequency }\end{array}$ & $\begin{array}{c}\text { Stride } \\
\text { length }\end{array}$ & $\begin{array}{c}\text { Turn } \\
\text { in }\end{array}$ \\
\hline Event time & $-.50^{*}$ & & & & & & & \\
Start time & $-.49^{*}$ & $.69^{*}$ & & & & & & \\
End time & $-.42^{*}$ & $.78^{*}$ & $.55^{*}$ & & & & & \\
Average velocity & $.42^{*}$ & $-.98^{*}$ & $-.58^{*}$ & $-.72^{*}$ & & & & \\
Stride frequency & -.25 & .29 & $.41^{*}$ & .17 & -.27 & & & \\
Stride length & $.35^{*}$ & $-.58^{*}$ & $-.56^{*}$ & $-.39^{*}$ & $.58^{*}$ & $-.94^{*}$ & & \\
Tum in & $-.42^{*}$ & $.88^{*}$ & $.63^{*}$ & $.68^{*}$ & $-.82^{*}$ & .23 & $-.47^{*}$ & \\
Tum out & $-.66^{*}$ & $.84^{*}$ & $.76^{*}$ & $.63^{*}$ & $-.75^{*}$ & .31 & $-.53^{*}$ & $.75^{*}$ \\
& & & & & & & & \\
\hline
\end{tabular}

*Significant $(p<.05)$.

ing that stature was a positive factor toward successful swimming performance; thus, as height increased, final time decreased. These results indicate that across all events the factor of height accounts for between $25 \%$ and $56 \%$ of the variability in final time. The strong link between height and final time has been demonstrated by Kennedy et al. (1990) and Chengalur and Brown (1992). The present finding was highlighted by the fact that height was significantly correlated with SL, TI, TO, and ET in every instance. These results are not surprising when one considers the inherent advantage that height offers in the execution of a start, a turn, a finish, or a single swimming stroke. Finally, the men's correlations were higher than the women's in every case but one ( $200 \mathrm{~m}$, height vs. TO), possibly pointing to the greater importance of stature (for men) in the execution of these race segments. 
Conversely, the factors of age and SR exhibited very low $r$ values when correlated with FT. Specifically, $r$ values for age versus FT ranged from -.03 to -.29 . Moreover, age was significantly correlated $(r=-.47)$ with a racing factor (ST) in only one event, the men's 50-m freestyle. These findings are contrary to earlier research that has shown age to be significantly correlated with final time, for example, Kennedy et al. (1990) and Chengalur and Brown (1992). Correlations between SR and FT were also low, ranging from .01 to .29. Furthermore, SR versus TO (women's 100,r $=.51$ ) and SR versus ST (women's 200, $r=.41$ ) were the only instances where SR was significantly correlated with a racing component. SR and FT have, on occasion, shown strong relationships in various strokes, including freestyle, so the low SR versus FT correlations found here are not necessarily in agreement with previous work.

These correlations and their interpretation have been influenced by two factors. The first concerns the large number of correlations (over 90) and their effect on the probability associated with the significance level. In many cases, however, the $r$ values were well beyond the values required for statistical significance, thus minimizing this as a limitation. Second, although the various time components are independent, they comprise the final time; consequently, they are not independent of FT and thus violate a basic assumption of correlational analysis. In spite of this limitation, the magnitude of these correlations (most $>.80$ ) still supports the fact that the successful swimmers tend to be the fastest over each of the timed phases.

\section{Event and Gender Comparisons}

The results of the 50-, 100-, and 200-m events were compared by a series of ANOVAs. Scheffe tests were subsequently performed to evaluate the differences. The results indicate the following significant trends for both men and women. As the race distance increased from 50 to $200 \mathrm{~m}$, the SR and AV decreased while the SL increased. Significant increases were also observed for the time values ST, ET, TI, and TO. Men and women differed significantly in every category at each race distance. Specifically, at the 50-m race distance, the men were $9 \%$ older, $8 \%$ heavier, and $12 \%$ taller, on average, than the women. The differences in age, weight, and height between men and women were $10 \%, 8 \%$, and $9 \%$ at $100 \mathrm{~m}$, and $9 \%, 8 \%$, and $9 \%$ at $200 \mathrm{~m}$, respectively.

The average age of the swimmers in both groups was lower as race distance increased, while average weight and height remained relatively constant. An examination of race components revealed that SRs were not significantly different (approximately 1-2\%) between sexes at any race distance. However, FT differences between men and women were $9.0 \%$ for the $50-\mathrm{m}$ freestyle, $9.1 \%$ for the 100 , and $9.2 \%$ for the 200 . Not surprisingly, average race velocity differences between genders were nearly identical, with corresponding percentages of $9.1 \%$, $9.1 \%$, and $9.3 \%$. Gender comparisons of average starting time, average finishing time, average turning times, and average stroke length were also of similar magnitudes: $8.6-9.2 \%$ for ST, $9.0-9.4 \%$ for ET, $9.0-9.2 \%$ for TI, $8.8-8.9 \%$ for TO, and $9.0-9.4 \%$ for SL. The implication here is that the approximately $9 \%$ FT difference between men and women can be equally accounted for in each of the race components examined. 


\section{Discussion}

The present investigation, similar to a project conducted at the 1988 Seoul Olympic Games, represents an ongoing, but more comprehensive, analysis of elite swimmers in Olympic competition. While the eventual product of this study will examine nearly all 14 individual swimming events performed at Barcelona, this initial paper focused on 3 events. A large database, gathered from the performances of 335 male and female athletes in the 50-, 100-, and 200-m freestyle events, provided an ideal opportunity to (a) examine the intercorrelations of nine experimental variables, (b) compare and contrast male and female competitors, (c) assess differences among the three race distances, and (d) observe performance trends and changes in the physical characteristics of swimmers across successive Olympic Games.

Intercorrelations revealed several significant relationships, many of which confirmed previous analyses. Height and SL demonstrated similarly significant positive relationships with FT. Moreover, height was clearly, positively related to SL. These findings, which correspond to other recent work, further elucidate the relationships among these variables and strengthen the recognition of height as a primary physical attribute of successful elite swimmers in the freestyle events. Furthermore, the strong negative correlations between FT and ST, ET, TI, and TO, and between height and ST, ET, TI, and TO, offered even greater support for the importance of stature as a determinant of race performance. This was especially true in the men's events, where correlations were relatively high at all three race distances.

Men and women were significantly different in all variables examined except SR. The men were typically $9-12 \%$ taller, $8-9 \%$ older, and $9 \%$ faster than the women. At the same time, the men's SLs, STs, ETs, TIs, and TOs were, on average, $8.5-9.5 \%$ longer or faster than the women's. Thus, the homogeneity of these findings further suggests that height, SL, and FT (and the specific race components comprising the total time) are invariably linked together in the specific races examined. Interestingly, when comparisons are made between the performances at the 1988 and 1992 Olympic Games, the FTs in Barcelona are faster in each event, with the exception of the men's $200-\mathrm{m}$ freestyle. This, too, is the only event in which SL did not increase from one Olympic Games to the next and in which average height definitely decreased. Thus, when the average final time was faster, the SL always went up and the height stayed the same or increased.

This investigation, based on video recordings of the 50-, 100-, and 200-m freestyle swimming events at the 1992 Olympic Games, provides important information about elite male and female swimmers. These results, in combination with those generated during the 1988 Olympic Games and data to be obtained in future Olympic Games, provide the basis for evaluating the evolution of elite swimming performance.

\section{Conclusions}

The following conclusions have been drawn from the results of this investigation:

- Successful freestyle swimmers are characterized by longer stroke lengths, shorter time values over each race section, higher average swimming velocities, and greater stature (height). 
- Male freestyle swimmers, in comparison to their female counterparts, are older, are taller, are faster over each race phase, and demonstrate longer stroke lengths, while their rates are similar.

- As the race distance increases from 50 to $200 \mathrm{~m}$, stroke length and the time to complete each phase increase, while stroke rate and age of the swimmers decrease.

\section{References}

Chengalur, S.N., \& Brown, P.L. (1992). An analysis of male and female Olympic swimmers in the 200-meter events. Canadian Journal of Sport Sciences, 17, 104-109.

Clarys, J.P., Jiskoot, J., Rijken, H., \& Brouwer, P.J. (1974). Total resistance in water and its relationship to body form. In R.C. Nelson \& C.A. Morehouse (Eds.), Biomechanics $I V$ (pp. 187-196). Baltimore: University Park Press.

Craig, A.B., Jr., \& Pendergast, D.R. (1979). Relationships of stroke rate, distance per stroke and velocity in competitive swimming. Medicine and Science in Sport, 11, 278-283.

Craig, A.B., Jr., Skehan, P.L., Pawelczyk, J.A., \& Boomer, W.L. (1985). Velocity, stroke rate, and distance per stroke during elite swimming competition. Medicine and Science in Sport, 17, 625-634.

DeGaray, A.L., Levine, L., \& Carter, J.E.L. (1974). Genetic and anthropological studies of Olympic athletes. New York: Academic Press.

East, D.J. (1970). An analysis of stroke frequency, stroke length, and performance. New Zealand Journal of Health, Physical Education and Recreation, 3, 16-27.

Grimston, S.K., \& Hay, J.G. (1986). Relationship among anthropometric and stroking characteristics of college swimmers. Medicine and Science in Sports and Exercise, $18,60-68$.

Hay, J.G., \& Guimares, A.C.S. (1983, August/October). A quantitative look at swimming biomechanics. Swimming Technique, pp. 11-17.

Kennedy, P.K., Brown, P.L., Chengalur, S.N., \& Nelson, R.C. (1990). Analysis of male and female Olympic swimmers in the 100-meter events. International Journal of Sport Biomechanics, 6, 187-197.

Official swimming results of the XXV Olympiad at Barcelona. (1992). Unpublished report. (Available from Raul Arellano, Facultad de las Ciencias de la Educacion Fisica $Y$ el Deporte, Universidad de Granada, Carretera de Alfacar, 48, 18011 Granada, Spain.)

Poe, G.H. (1969). The relationship of selected anthropometric measurements to swimming time of college varsity swimmers in the fifty-yard front crawl stroke. Unpublished master's thesis, Springfield College, Springfield, MA.

Shotwell, F.L. (1972). The relationship of swimming speed to selected physical measurements. Unpublished master's thesis, Texas Technological University, Lubbock.

Smith, L.E. (1959). An investigation into the relationship between learn-to-swim achievement and general motor capacity of boys and girls between the ages of five and eleven years. Australian Physical Education Journal, 16, 5-12.

Smith, L. (1978). Anthropometric measurements and arm and leg speed performance of male and female swimmers as predictors of swim speed. Journal of Sports Medicine, 18, 153-168.

Stroup, F. (1964). Height, weight and swimming time. The Physical Educator, 21, 19. 
Copyright of Journal of Applied Biomechanics is the property of Human Kinetics Publishers, Inc. and its content may not be copied or emailed to multiple sites or posted to a listserv without the copyright holder's express written permission. However, users may print, download, or email articles for individual use. 